\title{
Clinical Utility of Small Dense LDL Cholesterol in Metabolic Syndrome
}

\author{
Wahid Ali", Mukesh Kumar, Kauser Usman, Mohd Tasleem and Mohd Wamique \\ Department of Pathology, King George's Medical University, Lucknow, U.P., India \\ *Corresponding author: Wahid Ali, Department of Pathology, King George's Medical University, Lucknow, U.P., India, Tel: +91-9198852343; E-mail: \\ aliwahid78@gmail.com
}

Received date: July 20, 2017; Accepted date: September 28, 2017; Published date: September 30, 2017

Copyright: ( 2017 Ali W, et al. This is an open-access article distributed under the terms of the Creative Commons Attribution License, which permits unrestricted use, distribution, and reproduction in any medium, provided the original author and source are credited.

\begin{abstract}
The metabolic syndrome (syndrome $X$, Insulin resistance syndrome) consists of a constellation of metabolic abnormalities that confer increased risk of cardiovascular disease (CVD) and diabetes mellitus (DM). The rising prevalence of overweight and obesity in India has a direct correlation with the increasing prevalence of obesityrelated co-morbidities, hypertension, the metabolic syndrome, dyslipidemia, type 2 diabetes mellitus (T2DM) and cardiovascular disease (CVD). Small dense low density lipoprotein (sdLDL) also represents a marker for diagnosis and severity of the metabolic syndrome. Additionally, it has been suggested that the sdLDL/LDL ratio correlates with various parameters associated with MS rather than the LDL-C or sdLDL-C levels, thus possibly representing a more useful clinical indicator. Total 72 symptomatic cases of either sex, age between 20-80 yrs were recruited, of which, 38 were with MS and 34 were with metabolic syndrome with type 2 DM (MSwT2DM). The lipids and lipoproteins, including sdLDL by homogeneous assay, were determined in controls, MS and T2DM patients. In this study, the mean value of total cholesterol was higher in MS (142.88 \pm 7.15$)$ and MSwT2DM (171.16 \pm 11.36$)$ compared to normal subjects $(109.41 \pm 4.97)$ which was found statistically significant $(p<0.001)$. The mean sdLDL level and sdLDL/HDL ratio of three groups, there was significant difference in sdLDL level and sdLDL/HDL ratio among the groups, there was different and higher mean sdLDL level in both case groups as compared to normal control group. Furthermore, mean sdLDL level was also found significantly $(p<0.001)$ different and higher in MSwT2DM as compared to MS. It is concluded that LDL particle size such as sdLDL concentration has a positive correlation in increase in MS and diabetes mellitus in comparison to normal subjects.
\end{abstract}

Keywords: Metabolic syndrome (MS); Type 2 diabetes mellitus (T2DM); Cardiovascular disease (CVD); sdLDL

\section{Introduction}

The metabolic syndrome (syndrome $\mathrm{X}$, Insulin resistance syndrome) consists of a constellation of metabolic abnormalities that confer increased risk of cardiovascular disease (CVD) and diabetes mellitus (DM) $[1,2]$. The criteria for the metabolic syndrome have evolved since the original definition by the World Health Organization in 1998, reflecting growing clinical evidence and analysis by a variety of consensus conferences and professional organizations [2]. The major features of the metabolic syndrome include central obesity, hypertriglyceridemia, low high-density lipoprotein (HDL) cholesterol, hyperglycemia and hypertension.

The criteria for metabolic syndrome became uniform with the establishment of National Cholesterol Education Programme: Adult Treatment Panel III (NCEP: ATP III) and International Diabetes Federation (IDF) guidelines [3,4]. The prevalence of metabolic syndrome varies around the world. In general, the prevalence of metabolic syndrome increases with the age. The highest recorded prevalence worldwide is in Native Americans, with nearly $60 \%$ of women ages 45-49 and 45\% of men ages 45-49 meeting National Cholesterol Education Program and Adult Treatment Panel III (NCEP: ATP III) criteria [5]. Almost 30-65\% of adult urban Indians are either overweight or obese or have abdominal obesity [6]. The rising prevalence of overweight and obesity in India has a direct correlation with the increasing prevalence of obesity-related co-morbidities, hypertension, the metabolic syndrome, dyslipidemia, type 2 diabetes mellitus and cardiovascular disease (CVD) $[7,8]$. The clinical relevance of the metabolic syndrome is related to its role in the development of cardiovascular disease.

Two recent prospective population-based studies confirmed that the metabolic syndrome identified a high-risk group of persons who would have been missed by only consideration of the conventional risk factors $[9,10]$. The incidence of coronary disease along with carotid atherosclerosis is higher in patients with metabolic syndrome along with higher mortality from all such causes. Although for many obese patients the risk of developing metabolic syndrome is quite evident, but studies also show that the risk of having metabolic syndrome increases steeply even within the overweight or the "pre obese" range [11]. Thus, it is important to recognize the importance of metabolic syndrome.

LDL varies in size, density and metabolic characteristics and comprises at least four distinct subclasses (large LDL-I, medium LDLII, small LDL-III and very small LDL-IV). Although the association between Insulin Resistance (IR) and increased LDL-C levels is not typical, elevated sdLDL levels with lower large LDL concentrations are associated with reduced insulin sensitivity and increased adiposity [12-14]. Generally two phenotypes have been described: pattern A, with a higher proportion of larger, more buoyant or medium-sized $\mathrm{LDL}$, and pattern $\mathrm{B}$, with a predominance of $\operatorname{sdLD}$ [15]. In relation to large buoyant LDL, sdLDL particles are taken up more easily by arterial tissue, show lower affinity for the LDL receptor, have a longer half-life in plasma and greater oxidative and glycation susceptibility, suggesting a link between sdLDL particles and atherogenesis $[16,17]$. 
In different metabolic diseases (e.g. polycystic ovarian syndrome, growth hormone $(\mathrm{GH})$ deficiency [18-20] and in women with gestational diabetes [21] increased levels of sdLDL are also found. sdLDL also represents a marker for diagnosis and severity of the metabolic syndrome $[22,23]$. Additionally, it has been suggested that the sdLDL-C/LDL-C ratio correlates with various parameters associated with metabolic syndrome rather than the LDL-C or sdLDL$\mathrm{C}$ levels alone, thus possibly representing a more useful clinical indicator [24].

The aim of this study was to correlate the lipid profile in metabolic syndrome with special reference to sdLDL in a selected healthy Indian population and compared with metabolic syndrome (MS) and metabolic syndrome with type 2 Diabetes Mellitus (MSwT2DM) patients.

\section{Material and Methods}

\section{Study subjects}

The study was carried out at Department of Medicine, Department of Pathology, King Georg's Medical University, Lucknow, India from August 2015 - July 2016. A total of 92 subjects were selected with three groups (Normal: $n=20$, MS: $n=38$, and MSwT2DM: $n=34$ ). Patients written consent proforma was obtained and approved by institutional ethical committee, King George's Medical University, Lucknow, India. Thyroid disease, nephrotic syndrome, chronic liver disease, drug causing dyslipidemia was excluded from this study. IDF criteria fulfilled subjects were used for study. Metabolic syndrome subjects were diagnosed according to the IDF criteria, which was visceral obesity (waist circumference $\geq 94 \mathrm{~cm}$ in men, $\geq 80 \mathrm{~cm}$ in women) plus two or more following components: (a) Fasting triglycerides $\geq$ $150 \mathrm{mg} / \mathrm{dL}$. (b) Systolic blood pressure $\geqq 130 \mathrm{~mm} \mathrm{Hg}$ and/or diastolic blood pressure $\geqq 85 \mathrm{~mm} \mathrm{Hg}$ and (c) a fasting plasma glucose $\geqq 110$ $\mathrm{mg} / \mathrm{dl}$ or the prescribed use of an antidiabetic agent.

\section{Laboratory measurements}

Serum total cholesterol, High Density Lipoprotein Cholesterol (HDL-C), Triglyceride (TG) and Low Density Lipoprotein Cholesterol (LDL-C) was estimated by using ELITech Clinical Systems kit using fully automated analyser (Selectra XL) with proper control and calibrators by using Enzymatic-colorimetric, Trinder end point method. Glucose was measured with an Enzymaticcolorimetric,Trinder-kinetic methods. The sLDL-EX "SEIKEN" test kit was used for the quantitative determination of sdLDL-C by using automated chemistry analyzers capable of accommodating two-reagent assays.

\section{Statistical analysis}

Statistical analyses were conducted with the Microsoft Office Excel 2007, SPSS (Statistical Package for Social Sciences) Version 15.0. All values are expressed as the median. Linear relations between TG, LDL, HDL, sdLDL and large LDL were evaluated by linear regression models and Spearman's correlation coefficients in all of the subjects participating in this study.

\section{Results}

The present study determines association of sdLDL with lipid profile in patients with metabolic syndrome. Total 72 symptomatic cases of either sex, age between 20-80 yrs were recruited, of which, 38 were with MS and 34 were with MSwT2DM. Total 20, age and sex matched normal healthy subjects were also recruited as "Normal" control group. Thus, study comprised of total 92 subjects with three groups (Normal: $\mathrm{n}=20$, MS: $\mathrm{n}=38$, and MSwT2DM: $\mathrm{n}=34$ ).

The basic characteristics (age, sex, religion, occupation, residence, smoking and alcohol) of the three groups at enrollment are summarized in Table 1. The age of Normal, MS and MSwT2DM ranged from $29-67 \mathrm{yrs}, 32-80 \mathrm{yrs}$ and $20-80 \mathrm{yrs}$ respectively with mean $( \pm \mathrm{SD}) 51.25 \pm 2.45 \mathrm{yrs}, 53.76 \pm 2.02 \mathrm{yrs}$ and $52.21 \pm 2.20 \mathrm{yrs}$ respectively and median 51 yrs, 52 yrs and 50 yrs respectively. The mean age of MS group was slightly higher than other groups. Comparing the mean age of three groups, ANOVA showed similar age among the groups $(\mathrm{F}=0.31, \mathrm{p}=0.737)$ i.e. there was no significant difference among the groups. Further, there were 10 (50.0\%) females and $10(50.0 \%)$ males in Normal group while it was 20 (52.6\%) and 18 (47.4\%) respectively in MS group and $16(47.1 \%)$ and 18 (52.9\%) respectively in MSwT2DM group. Comparing the sex proportions $(\mathrm{M} / \mathrm{F})$ of three groups, $\chi^{2}$ test showed similar sex proportions among the groups $\left(\chi^{2}=0.22, p=0.895\right)$ i.e. there was no significant difference among the groups. In other words, subjects of three groups were age and sex matched and thus comparable and may also not influence the outcome measures. Moreover, there was no difference of religion, occupation and residence among the groups i.e. they were found to be statistically nonsignificant. However, smoking and alcohol frequency were different significantly $(\mathrm{p}<0.05$ or $\mathrm{p}<0.01)$ higher in cases (MS and MSwT2DM) as compared to Normal control group, may be because of risk factors of MS.

The anthropometric measurements of the three groups were summarized in Table 2. Comparing the mean anthropometric measurements of the three groups, ANOVA showed significantly $(\mathrm{p}<0.01$ or $\mathrm{p}<0.001)$ different mean measurements among the groups (Table 2). Further, Tukey test showed that the mean height in both the case groups (MS and MSwT2DM) was significantly $(\mathrm{p}<0.05$ or $\mathrm{p}<0.01$ ) lower as compared to normal control group but it did not differ between the cases (MS and MSwT2DM). In contrast, mean weight, BMI, WC, HC and WHR was significantly higher $(\mathrm{p}<0.001)$ in both the case groups as compared to normal group but was not different ( $p>0.05)$ between the cases i.e. found to be statistically non-significant.

The fasting lipid profile (TC, TG, VLDL, LDL, HDL, non HDL-C, non HDL-C/HDL, LDL/HDL and TC/HDL) levels of three groups were comparing in Table 3 . ANOVA showed significantly $(\mathrm{p}<0.05$ or $\mathrm{p}<0.001$ ) different lipid profile levels among the groups. Further, Tukey test showed significantly $(\mathrm{p}<0.05$ or $\mathrm{p}<0.001)$ higher lipid profile levels in both the case groups as compared to normal control group except VLDL and LDL.

The mean sdLDL level and sdLD/HDL ratio of three groups, ANOVA showed significant $(\mathrm{p}<0.001)$ difference in sdLDL level and sdLD/HDL ratio among the groups (Table 4). Further, Tueky test showed significantly $(\mathrm{p}<0.001)$ higher mean sdLDL level in both case groups as compared to normal control group. Furthermore, mean sdLDL level was also found significantly $(\mathrm{p}<0.001)$ different and higher in MSwT2DM as compared to MS. In contrast, mean sdLD/HDL ratio was found higher in both case groups as compared to Normal control group. 
Citation: Ali W, Kumar M, Usman K, Tasleem M, Wamique M (2017) Clinical Utility of Small Dense LDL Cholesterol in Metabolic Syndrome. J

\begin{tabular}{|c|c|c|c|c|c|}
\hline Variables & Normal $(n=20)(\%)$ & MS $(n=38)(\%)$ & MSwT2DM (n=34) (\%) & $\mathrm{F} / \mathrm{X}^{2}$ value & $P$ value \\
\hline Age (yrs) & $51.25 \pm 2.45$ & $53.76 \pm 2.02$ & $52.21 \pm 2.20$ & 0.31 & 0.737 \\
\hline \multicolumn{6}{|l|}{ Sex } \\
\hline Female & $10(50.0)$ & $20(52.6)$ & $16(47.1)$ & 0.22 & 0.895 \\
\hline Male & $10(50.0)$ & $18(47.4)$ & $18(52.9)$ & & \\
\hline \multicolumn{6}{|l|}{ Religion } \\
\hline Hindu & $18(90.0)$ & $31(81.6)$ & $30(88.2)$ & 1.02 & 0.602 \\
\hline Muslim & $2(10.0)$ & $7(18.4)$ & $4(11.8)$ & & \\
\hline \multicolumn{6}{|c|}{ Occupation } \\
\hline Farmer & $2(10.0)$ & $4(10.5)$ & $4(11.8)$ & 1.99 & 0.921 \\
\hline Housewife & $10(50.0)$ & $19(50.0)$ & $15(44.1)$ & & \\
\hline Job & $6(30.0)$ & $13(34.2)$ & $10(29.4)$ & & \\
\hline No job & $2(10.0)$ & $2(5.3)$ & $5(14.7)$ & & \\
\hline \multicolumn{6}{|l|}{ Residence } \\
\hline Rural & $8(40.0)$ & $17(44.7)$ & $13(38.2)$ & 0.33 & 0.848 \\
\hline Urban & $12(60.0)$ & $21(55.3)$ & $21(61.8)$ & & \\
\hline \multicolumn{6}{|l|}{ Smoking } \\
\hline No & $14(70.0)$ & $9(23.7)$ & $9(26.5)$ & 14.03 & 0.001 \\
\hline Yes & $6(30.0)$ & $29(76.3)$ & $25(73.5)$ & & \\
\hline \multicolumn{6}{|l|}{ Alcohol } \\
\hline No & $17(85.0)$ & $24(63.2)$ & $16(47.1)$ & 7.73 & 0.021 \\
\hline Yes & $3(15.0)$ & $14(36.8)$ & $18(52.9)$ & & \\
\hline
\end{tabular}

Table 1: Clinical characteristics for patients of metabolic syndrome (MS), metabolic syndrome with type II diabetes mellitus (MSwT2DM) and healthy control (Mean $\pm \mathrm{SD}$ ).

\begin{tabular}{|c|c|c|c|c|c|}
\hline Variables & Normal $(n=20)$ & MS (n=38) & MSwT2DM (n=34) & $F^{a}$ & $P^{b}$ \\
\hline Height $(\mathrm{cm})$ & $162.40 \pm 0.80$ & $158.55 \pm 0.91$ & $158.29 \pm 0.73$ & 5.52 & 0.006 \\
\hline Weight (kg) & $60.35 \pm 1.20$ & $82.13 \pm 1.13$ & $80.35 \pm 0.93$ & 93.37 & $<0.001$ \\
\hline BMI $\left(\mathrm{kg} / \mathrm{m}^{2}\right)$ & $22.89 \pm 0.27$ & $32.75 \pm 0.36$ & $32.12 \pm 0.31$ & 205.06 & $<0.001$ \\
\hline WC (cm) & $77.80 \pm 1.05$ & $105.32 \pm 1.18$ & $102.65 \pm 1.19$ & 123.09 & $<0.001$ \\
\hline $\mathrm{HC}(\mathrm{cm})$ & $93.30 \pm 1.17$ & $110.95 \pm 1.08$ & $108.68 \pm 1.24$ & 55.1 & $<0.001$ \\
\hline WHR & $0.84 \pm 0.011$ & $0.95 \pm 0.005$ & $0.94 \pm 0.004$ & 100.97 & $<0.001$ \\
\hline
\end{tabular}

Table 2: Anthropometric measurements for patients of metabolic syndrome (MS), metabolic syndrome with type II diabetes mellitus $(\mathrm{MSwT} 2 \mathrm{DM})$ and healthy control (Mean $\pm \mathrm{SD})$. 
Citation: Ali W, Kumar M, Usman K, Tasleem M, Wamique M (2017) Clinical Utility of Small Dense LDL Cholesterol in Metabolic Syndrome. J

Page 4 of 6

\begin{tabular}{|c|c|c|c|c|c|}
\hline Variables & Normal $(n=20)$ & MS (n=38) & MSwT2DM $(n=34)$ & Fa value & $\mathrm{Pb}$ Value \\
\hline $\mathrm{TC}(\mathrm{mg} / \mathrm{dL})$ & $109.41 \pm 4.97$ & $142.88 \pm 7.15$ & $171.16 \pm 11.36$ & 9.59 & $<0.001$ \\
\hline TG (mg/dL) & $104.17 \pm 7.24$ & $176.56 \pm 10.12$ & $193.18 \pm 11.41$ & 15.18 & $<0.001$ \\
\hline VLDL (mg/dL) & $20.83 \pm 1.45$ & $35.31 \pm 2.02$ & $38.64 \pm 2.28$ & 4.48 & 0.014 \\
\hline LDL (mg/dL) & $56.55 \pm 4.17$ & $72.53 \pm 5.68$ & $86.70 \pm 7.70$ & 4.37 & 0.015 \\
\hline $\mathrm{HDL}(\mathrm{mg} / \mathrm{dL})$ & $51.73 \pm 1.00$ & $29.31 \pm 2.49$ & $33.97 \pm 3.17$ & 14.86 & $<0.001$ \\
\hline Non HDL-C (mg/dL) & $57.69 \pm 4.40$ & $113.57 \pm 6.07$ & $137.19 \pm 11.56$ & 17.11 & $<0.001$ \\
\hline Non HDL-C/HDL & $1.11 \pm 0.08$ & $4.61 \pm 0.39$ & $5.27 \pm 0.76$ & 12.11 & $<0.001$ \\
\hline LDL/HDL & $1.09 \pm 0.08$ & $2.81 \pm 0.25$ & $3.04 \pm 0.31$ & 12.03 & $<0.001$ \\
\hline $\mathrm{TC} / \mathrm{HDL}$ & $2.11 \pm 0.08$ & $5.61 \pm 0.39$ & $6.27 \pm 0.76$ & 12.11 & $<0.001$ \\
\hline
\end{tabular}

Table 3: Lipid profile for patients of metabolic syndrome (MS), metabolic syndrome with type II diabetes mellitus (MSwT2DM) and healthy control (Mean $\pm \mathrm{SD})$.

\begin{tabular}{|l|l|l|l|l|l|}
\hline Variables & $\begin{array}{l}\text { Normal } \\
(\mathbf{n = 2 0})\end{array}$ & MS (n=38) & $\begin{array}{l}\text { MSwT2DM } \\
(\mathbf{n = 3 4 )}\end{array}$ & Fa $^{\mathrm{a}}$ & $\mathbf{P}^{\mathrm{b}}$ Value \\
\hline sdLDL (mg/dL) & $20.10 \pm 1.45$ & $\begin{array}{l}34.06 \\
1.36\end{array}$ & $42.51 \pm 0.93$ & 64.31 & $<0.001$ \\
\hline sdLDL/HDL & $0.39 \pm 0.03$ & $1.43 \pm 0.13$ & $1.56 \pm 0.13$ & 20.46 & $<0.001$ \\
\hline
\end{tabular}

Normal, Healthy control; MS, Metabolic Syndrome; MSwT2DM, Metabolic Syndrome with Type 2 Diabetes Mellitus.

aANOVA test; ${ }^{b}$ significance $p<0.05, p<0.01$

Table 4: sdLDL level for patients of metabolic syndrome (MS), metabolic syndrome with type II diabetes mellitus (MSwT2DM) and healthy control (Mean \pm SD).

To find out that the sdLDL may be associated to the disease (MS and MSwT2DM), the Pearson correlation analysis was done between sdLDL and confounding risk variables i.e. demographic, anthropometric measurements, blood pressure, FBG, hematological parameters and lipid profile. The Pearson correlation analysis showed a significant and positive (direct) correlation of sdLDL with weight

$(\mathrm{r}=0.61, \mathrm{p}<0.001)$, BMI $(\mathrm{r}=0.60, \mathrm{p}<0.001)$, WC $(\mathrm{r}=0.54, \mathrm{p}<0.001), \mathrm{HC}$ $(\mathrm{r}=0.46, \mathrm{p}<0.001)$, WHR $(\mathrm{r}=0.53, \mathrm{p}<0.001)$, SBP $(\mathrm{r}=0.36, \mathrm{p}<0.001)$, DBP $(r=0.39, p<0.001)$, FBG $(r=0.51, p<0.001)$, TLC $(r=0.26, p<0.05)$, TC $(r=0.25, p<0.05), T G(r=0.34, p<0.001)$, VLDL $(r=0.34, p<0.001)$, LDL $(r=0.25, p<0.05)$, non HDL-C $(r=0.32, p<0.01)$, non HDL-C/HDL $(\mathrm{r}=0.25, \mathrm{p}<0.05), \mathrm{LDL} / \mathrm{HDL}(\mathrm{r}=0.33, \mathrm{p}<0.01), \mathrm{TC} / \mathrm{HDL} \quad(\mathrm{r}=0.25$, $\mathrm{p}<0.05)$ and sdLDL/HDL $(\mathrm{r}=0.58, \mathrm{p}<0.001)$. In contrast, sdLDL showed a significant and negative (inverse) correlation with fasting platelet count $(\mathrm{PC}) \quad(\mathrm{r}=-0.54, \mathrm{p}<0.001)$, HDL $\quad(\mathrm{r}=-0.24, \mathrm{p}<0.05)$ indicating that as these decreases, sdLDL may increases or vice-aversa. However, sdLDL did not $(p>0.05)$ correlate well with age, sex, height and $\mathrm{Hb}$ suggesting that these may not be associated to sdLDL.

sdLDL showed significant diagnostic accuracy (AUC $=0.960$, $\mathrm{p}<0.001)$ when evaluated between normal and total cases/disease (MS + MswT2DM) as at cut off value of $>28 \mathrm{mg} / \mathrm{dL}$, discriminating the subjects of two groups with high $81.94 \%$ sensitivity (95\% $\mathrm{CI}=71.1-90.0)$ and highest $100 \%$ specificity $(95 \% \mathrm{CI}=83.0-100.0)$ and with $100 \%$ positive predictive value but low $60.6 \%$ negative predictive value (Table 5 and Figure 1).

\begin{tabular}{|c|c|c|c|c|c|c|c|}
\hline $\begin{array}{l}\text { ROC } \\
\text { Normal vs. }\end{array}$ & $\begin{array}{l}\text { Cut off value } \\
(\mathrm{mg} / \mathrm{dL})\end{array}$ & AUC & $p$ value & Sensitivity $(95 \% \mathrm{Cl})$ & Specificity $(95 \% \mathrm{CI})$ & $+P V$ & -PV \\
\hline MS & $>24.0$ & 0.924 & $<0.001$ & $94.74(82.2-99.2)$ & $75.00(50.9-91.2)$ & 87.8 & 88.2 \\
\hline MSwT2DM & $>28.0$ & 1 & $<0.001$ & $100.00(89.6-100.0)$ & $100.00(83.0-100.0)$ & 100 & 100 \\
\hline Total & $>28.0$ & 0.96 & $<0.001$ & $81.94(71.1-90.0)$ & $100.00(83.0-00.0)$ & 100 & 60.6 \\
\hline
\end{tabular}

$\mathrm{ROC}$, receiver operating characteristic; AUC, area under cure; $\mathrm{Cl}$, confidence interval; +PV, positive predictive value; - $\mathrm{PV}$, negative predictive value.

MS, Metabolic Syndrome; MSwT2DM, Metabolic Syndrome with Type 2 Diabetes Mellitus.

Table 5: Diagnostic accuracy of sdLDL to discriminate normal and cases. 


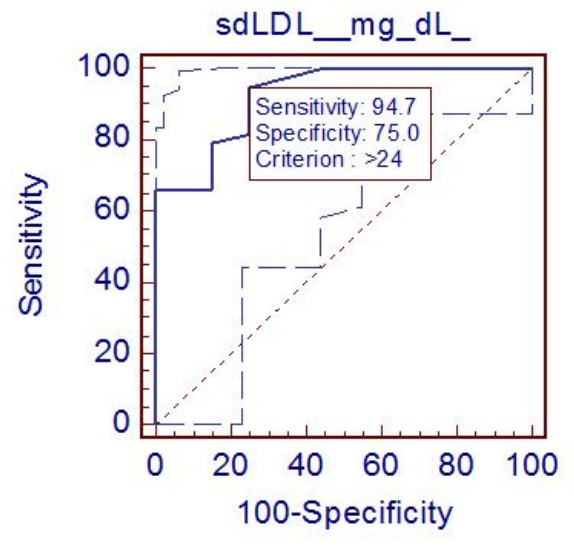

A

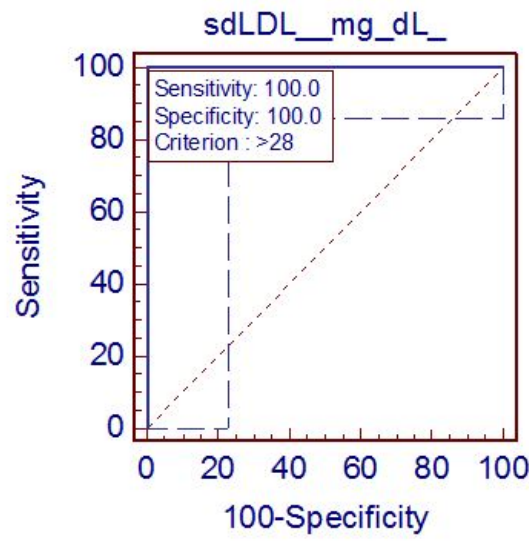

$\mathrm{B}$

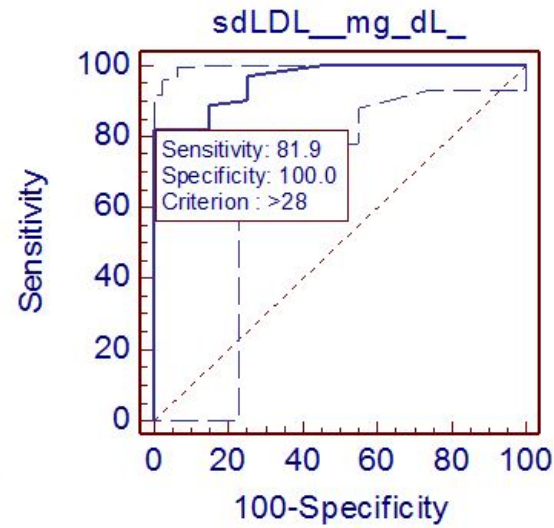

$\mathrm{C}$

Figure 1: ROC curves and corresponding AUCs of sdLDL to discriminate (A), healthy control and MS cases; (B), healthy control and MSwT2DM cases; (C), healthy control and both (MS+ MSwT2DM) cases. Abbreviations: AUC: area under the curve; CI: confidence interval; ROC: receiver operating characteristic.

\section{Discussion}

The study highlights the following findings 1) mean lipid profile was significantly high in MS as compare to normal subject, except VLDL and LDL which was raised but not statistically significant. 2) The MS components significantly related to high sdLDL level and could be a valuable marker for diagnosis and severities of the MS. Asian Indians are at high risk population with respect to diabetes and cardiovascular diseases and the numbers are consistently on rise. Metabolic syndrome is a cluster of cardiometabolic risk factors like obesity, hypertension, hyperglycemia, hypertriglyceridemia and low HDL [10]. The present study was an observational cross-sectional study where various risk factors were assessed with metabolic syndrome, type-2 diabetes mellitus and its components i.e. age, sex, occupation, place of residence, anthropometric measurements, blood pressure, addiction habits, fasting lipid profile, fasting blood glucose, small dense LDL (sdLDL), hematological parameters ( $\mathrm{Hb}$, TLC, Platelet count ). The study was conducted after screening subjects on the basis of IDF criteria for diagnosis of MS. A total 92 subjects with three groups (Normal: $n=20, M S: n=38$, and MSwT2DM: $n=34$ ) were selected for this study. In our study, we examined the fasting lipid profiles (TC, TG, VLDL, LDL, HDL, non HDL-C, non HDL-C/HDL, LDL/HDL and TC/ HDL) which were associated with metabolic syndrome and its components. Fasting lipid profile of three groups showed significantly $(\mathrm{P}<0.001)$ different mean fasting triglycerides and fasting high-density lipoprotein among the groups. Kawamoto et al. [25] showed that low levels of high-density lipoprotein cholesterol (HDL-C) and higher levels of triglycerides (TG) had strong association with metabolic syndrome, which is supporting our study. We detected a strong association between sdLDL score and metabolic syndrome. On comparing results of small dense LDL in metabolic syndrome in Indian population, our findings were also supported by study done by Kulkarni et al. [26,27]. The objective of their study was to examine whether the prevalence of smaller and denser LDL particles is increased in Asian Indians. They found that prevalence of small dense LDL type (subjects with major LDL subclass 5 or 6 ) was significantly higher in Asian Indians compared with white subjects (44\% versus 21\%; $\mathrm{P}<0.05)$. However, small dense LDL did not $(\mathrm{p}>0.05)$ correlate well with age, sex, height and $\mathrm{Hb}$ suggesting that these may not be associated with small dense LDL. There are some limitations for this study. Because of the crosssectional composition of the study, no factors/effect relationships can be made. Lifestyle factors like physical inactivity and their effect on occurrence of MS were not assessed. However, ours finding was significantly associated with MS.

In conclusion, sdLDL particles could be a valuable marker for diagnosis and severity of the MS. On the basis of our combined results it is concluded that LDL particle size such as sdLDL concentration has a positive correlation increase in metabolic syndrome, metabolic syndrome with diabetes mellitus in comparison to normal subjects. Thus, increased level of sdLDL as a single marker is highly predictive in metabolic syndrome and metabolic syndrome with diabetes mellitus.

\section{Acknowledgments}

The authors thank to honorable Vice Chancellor, KGMU and Head of the department, pathology, KGMU, Lucknow for their support and valuable discussions.

\section{Conflicts of Interest}

The authors declared no conflict of interest.

\section{References}

1. Reaven GM (1998) Role of insulin resistance in human disease. Diabetes 37: 1595-1607.

2. Alberti KG, Zimmet PZ (1998) Definition, diagnosis and classification of diabetes mellitus and its complications. Part 1: diagnosis and classification of diabetes mellitus. Provisional report of a WHO consultation. Diabetic medicine 15: 539-553.

3. Expert Panel on Detection E (2001) Executive summary of the Third Report of the National Cholesterol Education Program (NCEP) expert panel on detection, evaluation, and treatment of high blood cholesterol in adults (Adult Treatment Panel III). Jama 285: 2486-2497. 
Citation: Ali W, Kumar M, Usman K, Tasleem M, Wamique M (2017) Clinical Utility of Small Dense LDL Cholesterol in Metabolic Syndrome. J

4. IDF (2006) The IDF Consensus worldwide definition of the Metabolic Syndrome. International Diabetes Federation 10-11.

5. Ford ES, Ajani UA, McGuire LC, Liu S (2005). Concentrations of serum vitamin $\mathrm{D}$ and the metabolic syndrome among US adults. Diabetes care 28: 1228-1230.

6. Misra A, Khurana L (2008) Obesity and the metabolic syndrome in developing countries. J Clin Endocrinol Metab 93: s9-30.

7. Gupta R, Misra A (2007) Review: Type 2 diabetes in India: regional disparities. The British J Diab Vasc Dis 7: 12-16.

8. Isomaa BO, Almgren P, Tuomi T, Forsén B, Lahti K, et al. (2001) Cardiovascular morbidity and mortality associated with the metabolic syndrome. Diabetes care 24: 683-689.

9. Wortsman J, Matsuoka LY, Chen TC, Lu Z, Holick MF (2000) Decreased bioavailability of vitamin D in obesity. Am J Clin Nutr 72: 690-693.

10. Tzotzas T, Evangelou P, Kiortsis DN (2011) Obesity, weight loss and conditional cardiovascular risk factors. Obe rev 12: 282-289.

11. Vega GL (2001) Obesity, the metabolic syndrome, and cardiovascular disease. American heart journal 142: 1108-1116.

12. Nieves DJ, Cnop M, Retzlaff B, Walden CE, Brunzell JD, et al. (2003) The atherogenic lipoprotein profile associated with obesity and insulin resistance is largely attributable to intra-abdominal fat. Diabetes 52: 172-179.

13. Goff DC, D'Agostino RB, Haffner SM, Otvos JD (2005) Insulin resistance and adiposity influence lipoprotein size and subclass concentrations. Results from the Insulin Resistance Atherosclerosis Study. Metabolism. 54: 264-270.

14. Rizzo M, Rini GB, Berneis K (2007a). The clinical relevance of LDL size and subclasses modulation in patients with type-2 diabetes. Exp Clin Endocrino Diab 115: 477-482.

15. Berneis KK, Krauss RM (2002) Metabolic origins and clinical significance of LDL heterogeneity. J Lipid Res 43: 1363-1379.

16. Rizzo MA, Berneis K (2006) Low-density lipoprotein size and cardiovascular risk assessment. Qjm 99: 1-4.

17. Superko HR, Gadesam RR (2008) Is it LDL particle size or number that correlates with risk for cardiovascular disease? Curr Atheroscler Rep 10 377-385.
18. Rizzo M, Trepp R, Berneis K, Christ ER (2007b) Atherogenic lipoprotein phenotype and low-density lipoprotein size and subclasses in patients with growth hormone deficiency before and after short-term replacement therapy. Eur J Endocrinol 156: 361-367.

19. Rizzo M, Berneis K, Hersberger M, Pepe I, Di Fede G, et al. (2009) Milder forms of atherogenic dyslipidemia in ovulatory versus anovulatory polycystic ovary syndrome phenotype. Hum Reprod 24: 2286-2292.

20. Berneis K, Rizzo MA, Hersberger M, Rini GB, Di Fede G, et al. (2009) Atherogenic forms of dyslipidaemia in women with polycystic ovary syndrome. Int J Clin Pract 63: 56-62.

21. Rizzo MA, Berneis K, Altinova AE, Toruner FB, Akturk M, et al. (2008) Atherogenic lipoprotein phenotype and LDL size and subclasses in women with gestational diabetes. Diabet Med 25: 1406-1411.

22. Gazi I, Tsimihodimos V, Filippatos T, Bairaktari E, Tselepis AD, et al. (2006) Concentration and relative distribution of low-density lipoprotein subfractions in patients with metabolic syndrome defined according to the National Cholesterol Education Program criteria. Metabolism 55: 885-891.

23. Rizzo M, Berneis K (2007c) Small, dense low-density-lipoproteins and the metabolic syndrome. Diabetes Metab Res Rev 23: 14-20.

24. Satoh N, Wada H, Ono K, Yamakage H, Yamada K, et al. (2008) Small dense LDL-cholesterol relative to LDL-cholesterol is a strong independent determinant of hypoadiponectinemia in metabolic syndrome. Circ J 72: 932-939.

25. Kawamoto R, Tabara Y, Kohara K, Miki T, Kusunoki T, et al. (2011) Relationships between lipid profiles and metabolic syndrome, insulin resistance and serum high molecular adiponectin in Japanese community-dwelling adults. Lipids health dis 10:79.

26. Kulkarni KR, Markovitz JH, Nanda NC, Segrest JP (1999) Increased prevalence of smaller and denser LDL particles in Asian Indians. Arterioscler Thromb Vasc Biol 19: 2749-2755.

27. Fukushima Y, Hirayama S, Ueno T, Dohi T, Miyazaki T, et al. (2011) Small dense LDL cholesterol is a robust therapeutic marker of statin treatment in patients with acute coronary syndrome and metabolic syndrome. Clin Chim Acta 412: 1423-14277. 